This item was submitted to Loughborough's Research Repository by the author.

Items in Figshare are protected by copyright, with all rights reserved, unless otherwise indicated.

\title{
Attitudes toward sport psychology consulting in athletes: Understanding the role of culture and personality
}

PLEASE CITE THE PUBLISHED VERSION

http://psycnet.apa.org/doi/10.1037/spy0000103

\section{PUBLISHER}

(C) American Psychological Association (APA)

\section{VERSION}

AM (Accepted Manuscript)

\section{PUBLISHER STATEMENT}

This work is made available according to the conditions of the Creative Commons Attribution-NonCommercialNoDerivatives 4.0 International (CC BY-NC-ND 4.0) licence. Full details of this licence are available at: https://creativecommons.org/licenses/by-nc-nd/4.0/

\section{LICENCE}

CC BY-NC-ND 4.0

\section{REPOSITORY RECORD}

Ong, Nathanael C. H., and Chris G. Harwood. 2019. "Attitudes Toward Sport Psychology Consulting in Athletes: Understanding the Role of Culture and Personality”. figshare. https://hdl.handle.net/2134/26681. 
Attitudes towards sport psychology consulting in athletes: Understanding the role of culture and personality

Nathanael C. H. Ong

Singapore Sports Institute

Chris Harwood

Loughborough University

Author Note

Nathanael C. H. Ong, Department of Sport Psychology, Sport Science Centre,

Singapore Sports Institute.

Correspondence concerning this article should be addressed to Nathanael C. H. Ong, Singapore Sports Institute, 3 Stadium Drive, Singapore 397630. Email contact: natong89@hotmail.com. 


\section{Abstract}

2 The purpose of this study was to investigate how an athlete's Eastern-Western cultural

3 affiliation and personality are related to their perception of sport psychology and attitude

4 towards consultation with a sport psychology practitioner. Two hundred and nineteen athletes

5 from Western and Eastern cultures completed the Sport Psychology Attitudes-Revised form

6 (SPA-R; Martin et al., 2002) and the NEO-Five Factor Inventory (NEO-FFI; Costa \&

7 McCrae, 1992). Multivariate analysis of covariance (MANCOVA) revealed that Western

8 athletes had lesser stigma towards sport psychology consulting, greater personal openness,

9 and lesser preference for a consultant of the same race or culture than Eastern athletes.

10 Multiple linear regression analysis revealed that lower openness and conscientiousness

11 predicted greater stigma towards sport psychology consulting; higher neuroticism, conscientiousness, and openness predicted greater confidence in sport psychology consulting;

13 and lower openness predicted greater preference for working with a sport psychology

14 consultant of the same race or culture. These findings may prove valuable to applied sport

15 psychology practitioners, and aim to help them better understand the athletes and athletic 16 population to whom they offer their services. 
Attitudes towards sport psychology consulting in athletes: Understanding the role of personality and culture Despite the widespread acknowledgement that mental factors play a crucial role in sporting success (Connaughton, Wadey, Hanton, \& Jones, 2008; Gould \& Maynard, 2009; Greenleaf, Gould, \& Dieffenbach, 2001), there still exists degrees of resistance among athletes towards sport psychology consulting (Karageorghis \& Terry, 2011; Kremer \& Moran, 2012). It has been suggested by Ravizza (2001) that as a general rule of thumb, approximately one-third of athletes are not receptive to sport psychology consulting, onethird are indifferent, and only one-third are interested. Similarly, Green, Morgan and Manley (2012) found that even though most elite rugby league players agreed that sport psychology was important, many of them were reluctant to engage the help of a sport psychology consultant due to the fear of being judged by coaches and teammates. In view of the perceived resistance that exists towards sport psychology, Martin, Wrisberg, Beitel, and Lounsbury (1997) stated that research needed to be geared towards understanding the attitudes that athletes have towards sport psychology consulting, and investigate the factors that could potentially influence those attitudes. This line of enquiry would serve to inform how sport psychology consultants could make sport psychology more accessible and attractive to athletes, and also allow them to devise strategies to target athletes who may not be receptive to sport psychology (Martin et al., 1997).

\section{Previous Literature on Sport Psychology Attitudes}

In view of these observations, research has been conducted to determine the main factors that are involved in athletes' attitudes towards sport psychology consulting (Martin, Kellmann, Lavallee, \& Page, 2002). The first factor is stigma tolerance, which is the belief that athletes will be viewed negatively if they engage the help of a sport psychology consultant (Martin et al., 2002). This factor has a long history of support, with Ravizza 
1 (1988) stating that the negative connotation of sport psychology was the most significant

2 barrier facing sport psychology consultants. The second factor is confidence in sport

3 psychology consulting, which is the belief that sport psychology is actually helpful and will

4 benefit the athletes who engage with the process (Martin et al., 2002). Pain and Harwood

5 (2004) found that it is difficult for sport psychology consultants to quantify the impact of

6 their services, and this could cause athletes to be skeptical as to whether sport psychology can

7 truly help to improve their sporting performance. The third factor is personal openness,

8 which is the willingness of athletes to engage in sport psychology consulting (Martin et al.,

9 2002). Wrisberg, Simpson, Loberg, Withycombe, and Reed (2009) found that athletes who

10 had perceived past sport psychology experiences to be effective were more open to future

11 consultation, while the opposite was true for athletes who had negative past experiences. The

12 fourth factor is cultural preference, which is the preference of athletes to work with a

13 consultant who is from the same culture and background (Martin et al., 2002). Lubker, Visek,

14 Watson, and Singpurwalla (2012) supported this assertion when they found that a

15 consultant's race was one of the factors that influenced an athlete's attitude towards the

16 consultant.

After identifying various components that were involved in athletes’ sport psychology

attitudes, Martin, Zakrajsek, and Wrisberg (2012) created a framework known as the

Multidimensional Model of Sport Psychology Service Provision $\left(\mathrm{M}^{2} \mathrm{SP}^{2}\right)$, which sought to

20 illustrate the process by which athletes’ attitudes towards sport psychology consulting are

21 formed. In their model, they highlight various personal and situational factors that contribute

22 to athletes' receptivity towards sport psychology consulting. Firstly, there is a significant

23 amount of evidence to suggest that males are less receptive to sport psychology consulting

24 than females (Anderson, Hodge, Lavallee, \& Martin, 2004; Martin, 2005; Martin et al., 1997;

25 Martin, Lavallee, Kellmann, and Page, 2004; Wrisberg et al., 2009). It has been found that 
1 male athletes are more likely to stigmatise sport psychology consulting, have less confidence

2 in sport psychology consulting, have less personal openness towards sport psychology, and

3 prefer working with a consultant of the same race or ethnicity than female athletes (Anderson

4 et al., 2004; Martin, 2005; Martin et al., 1997, 2004). A common explanation given for this

5 observation is that social norms and cultural stereotypes dictate that male athletes should be

6 tough and masculine, and should not exhibit or disclose any emotional problems (Yambor \&

7 Connelly, 1991). The type of sport that athletes engage in has also been found to influence

8 their attitudes towards sport psychology consulting. Martin (2005) found that athletes who

9 played physical contact sports found sport psychology to be more stigmatising than non-

10 contact sport athletes. The explanation given for this finding was that athletes who

11 participated in physical contact sports are socialised to accept the pain and hurt that comes with the sport, and are not as willing to seek help as non-contact sport athletes (Martin, 2005; Vogel, Wade, \& Hackler, 2007). There is also evidence to suggest that an athlete's previous sport psychology experience can affect their subsequent attitudes towards sport psychology consulting (Anderson et al., 2004; Martin, 2005; Martin et al., 2004). It has also been found that effective past sport psychology consulting experiences were related to positive sport psychology attitudes in the athletes, while ineffective past experiences were related to negative sport psychology attitudes (Wrisberg et al., 2009). Culture and ethnicity have also been found to be significantly related to athletes’ attitudes towards sport psychology consulting. In one study, Martin et al. (2004) sought to 21 investigate the sport psychology attitudes of American, British, and German athletes. They 22 found several differences between athletes from the three nations, with American athletes more likely to stigmatise sport psychology consulting than British and German athletes; and

24 British athletes being more confident in sport psychology consulting, and identifying more 25 with consultants of similar culture than American and German athletes. Similar studies were 
1 conducted with athletes from New Zealand (Anderson et al., 2004) and Ireland (Lavallee,

2 Jennings, Anderson, \& Martin, 2005), and it was found that athletes from both countries had

3 positive attitudes towards sport psychology, and were open to engaging in sport psychology

4 consulting.

5

6

A notable trend in the body of literature reflects how the vast majority of research done on athletes’ sport psychology attitudes has been conducted in Western countries such as the United States, United Kingdom, Germany (Martin et al., 2004), New Zealand (Anderson et al., 2004), and Ireland (Lavallee et al., 2005); and there is very limited research that has been conducted in an Eastern context. This is a significant gap in literature, and several researchers (Anderson et al., 2004; Lavallee et al., 2005; Martin et al., 2004) have called for future research to explore the cultural differences that may exist between athletes from Eastern and Western cultures. One study that has been previously conducted in an Eastern context was by Naoi, Watson, Deaner, and Sato (2011), who found that Japanese athletes had a greater interest in receiving sport psychology help than American athletes, but were also less open to talking about personal issues, and preferred to work with a sport psychology consultant of the same race. However, one important limitation of the study was that it used a self-developed scale to measure sport psychology attitudes, and the scale did not have evidence for score validity or reliability demonstrated. It is worth noting here that the Sport Psychology Attitudes-Revised (SPA-R) questionnaire (Martin et al., 2002) has undergone more systematic evaluation of score validity and reliability.

At this juncture, we must highlight that even though previous researchers advocate comparisons between athletes from Eastern and Western cultures, this form of grouping strategy might in fact be too broad (Andersen, 1993). Therefore, the recommendation might be to narrow the comparison down to the main nationalities examined in this study (i.e., British vs Singaporean), in order to understand the fine nuances and unique characteristics 
1 that might exist in those specific groups. This is in line with current research in cultural sport

2 psychology (McGannon \& Johnson, 2009; Ryba, Stambulova, Si, \& Schinke, 2013; Schinke,

3 McGannon, Parham, \& Lane, 2012), which advocates the need to capture the complexity and

4 context of each specific culture group, so as to gain an accurate view of that particular group.

\section{Relationships between Personality and Help-Seeking Attitudes}

6 Despite previous efforts to investigate athletes’ attitudes towards sport psychology

7 consulting, one important factor that has yet to be explored is the personality of the athlete.

8 Several researchers (Lavallee et al., 2005; Martin, 2005; Martin et al., 2004) have suggested

9 that future research be conducted to explore how personality could affect sport psychology

10 attitudes in athletes. While there has been a lack of research done in the area of sport

11 psychology, there has been a significant amount of research done in counseling and helpseeking settings to suggest that personality could potentially affect sport psychology attitudes (Atik \& Yalcin, 2011; Kakhnovets, 2011; Seekles et al., 2012). A review of literature reveals that the vast majority of studies in this area have utilized the Five Factor Model (FFM) as the personality measure of choice (Friedman, Veazie, Chapman, Manning, \& Duberstein, 2013;

16 Klockner \& Hicks, 2008; Tsan \& Day, 2007; etc.). The FFM stipulates that there are five main dimensions of personality known as the Big Five personality traits, which comprise of extraversion, neuroticism, agreeableness, conscientiousness, and openness (McCrae \& John, 1992). Extraversion is characterised by outgoingness and sociability; neuroticism by emotional instability and mood swings; agreeableness by cooperation and prosocial tendencies; conscientiousness by organisation and detail-orientation; and openness by creativity and a willingness to try new things (McCrae \& John, 1992). In past research, the

23 Big Five personality traits have shown to be significantly related to counseling and help24 seeking attitudes. 
Individuals with high extraversion have been found to report more positive attitudes

2 towards help-seeking (Amirkhan, Risinger, \& Swickert, 1995; Atik \& Yalcin, 2011;

3 Kakhnovets, 2011), psychosocial support (Klockner \& Hicks, 2008), and counseling (Nocita

4 \& Stiles, 1986; Tsan \& Day, 2007). Researchers have proffered that extraverts are more

5 comfortable talking to other people, and would feel more at ease with counseling than

6 introverts (Atik \& Yalcin, 2011; Kakhnovets, 2011). Individuals with high neuroticism have

7 also been found to possess better attitudes towards help-seeking (Kakhnovets, 2011),

8 counseling (Seekles et al., 2012), healthcare use (Friedman et al., 2013), and mental health

9 treatment utilization (Hopwood et al., 2008). A common explanation given here is that

10 individuals who attain a low score on neuroticism are usually calm and even-tempered, and

11 would not require as much emotional support as those who are highly neurotic (Kakhnovets,

12 2011; Seekles et al., 2012). Individuals with high agreeableness have been shown to possess

13 more positive attitudes towards help-seeking (Atik \& Yalcin, 2011; Kakhnovets, 2011), and

14 seeking information about mental care (Seekles et al., 2012). Kakhnovets (2011) notes that

15 individuals low in agreeableness are often skeptical about the benefits of counseling, and are

16 less likely to want to receive help from others. Individuals with high conscientiousness have

17 been found to have poorer attitudes towards seeking practical support and skills training, with

18 the explanation that such individuals are self-disciplined and task-oriented, and may have

19 lesser need to seek help from others (Seekles et al., 2012). Finally, individuals with higher

20 openness were found to have more positive attitudes towards help-seeking (Atik \& Yalcin,

21 2011; Kakhnovets, 2011; Komiya, Good, \& Sherrod, 2000) and counseling (Bathje, Kim,

22 Rau, Bassiouny, \& Kim, 2014; Seekles et al., 2012). Individuals with high openness have

23 been hypothesised to be willing to try new things and explore whether counseling is able to

24 help them improve their situation (Atik \& Yalcin, 2011; Kakhnovets, 2011).

25 The Current Study: Aims and Hypotheses 
1 Given the aforementioned work in this area of sport psychology, and relevant

2 literature in counselling psychology, the objective of the present study was to extend this

3 field of research in the following ways. Firstly, we aimed to investigate whether and how

4 differences existed in the sport psychology attitudes of athletes from Western and Eastern

5 cultures. Although past research is limited in this area to a single study (Naoi et al., 2011), we

6 hypothesised that Eastern athletes would prefer working with consultants of the same culture,

7 have less openness towards sport psychology consulting, but have more confidence in sport

8 psychology consulting, and less stigma towards the discipline than Western athletes. In

9 addition, we also sought to investigate how athletes might differ in terms of their gender and

10 type of sport. Based on previous literature, we hypothesised that males will have less positive

11 attitudes towards sport psychology than females (Anderson et al., 2004; Martin, 2005; Martin

12 et al., 2004), and that contact sport athletes will have less positive attitudes towards sport

13 psychology than non-contact sport athletes (Martin, 2005).

14 The other aim of this study was to investigate how athletes’ Big Five personality traits 15 predicted their attitudes towards sport psychology consulting. Such findings would enable 16 applied sport psychology practitioners to better understand how athletes may respond to their 17 initial services, and help them to better cater their services (e.g., marketing, communication).

18 Based on previous research conducted in counseling and help-seeking settings (Atik \&

19 Yalcin, 2011; Kakhnovets, 2011; Seekles et al., 2012), it was hypothesised that high

20 extraversion, neuroticism, agreeableness, openness, and low conscientiousness would all

21 predict more positive attitudes towards sport psychology.

\section{Method}

\section{Measures}

SPA-R. The Sport Psychology Attitudes-Revised (SPA-R; Martin et al., 2002) is a

25 25-item questionnaire designed to measure attitudes towards sport psychology consulting. 
1 The questionnaire comprises of four scales: (a) stigma tolerance; (b) confidence in sport

2 psychology consulting; (c) personal openness; (d) cultural preference. Respondents are

3 required to report their attitudes and beliefs about sport psychology on a 7-point Likert scale

4 ranging from "strongly disagree” to "strongly agree”. A higher score in stigma tolerance

5 indicates that the individual has more stigma towards sport psychology consulting; a higher

6 score in confidence in sport psychology consulting indicates that the individual is more

7 confident in the benefits that sport psychology might provide; a higher score in personal

8 openness indicates that athletes are less open to seeking sport psychology consulting; and a

9 higher score in culture preference indicates that the individual prefers working with a sport

10 psychology consultant of the same race or culture. The SPA-R has shown to be a reliable

11 measure, with coefficient alphas ranging from 0.61 to 0.84 for all scales (Martin et al., 2002).

12 NEO-FFI. The NEO-Five Factor Inventory (NEO-FFI; Costa \& McCrae, 1992) is a

13 60-item questionnaire used to assess the Big Five personality traits. The questionnaire

14 comprises of five scales that represent each of the Big Five personality traits: (a)

15 extraversion; (b) neuroticism; (c) agreeableness; (d) conscientiousness; (e) openness.

16 Respondents are required to answer personality-related questions on a 5-point Likert scale

17 ranging from "strongly disagree” to "strongly agree”. A higher score for extraversion

18 indicates that the individual is more outgoing and sociable; a higher score for neuroticism

19 indicates that the individual is more prone to mood swings and emotional instability; a higher

20 score for agreeableness indicates that the individual is more trusting and cooperative; a higher

21 score for conscientiousness indicates that the individual is more self-disciplined and task

22 oriented; and a higher score in openness indicates that the individual is more creative and

23 imaginative. The NEO-FFI has shown to have construct validity, test-retest stability, with

24 internal consistency ranging from 0.68 to 0.86 (Costa \& McCrae, 1992).

25 Procedures 
After receiving ethical approval from the institutional review board, pilot tests were conducted with a small sample of athletes to evaluate the clarity and content of the online

3 Google Docs questionnaire. All of the athletes involved in the pilot tests gave feedback that

4 the online questionnaire was appropriate and suitable. Subsequently, the sport teams of

5 various universities, sport clubs, and sport institutes in the United Kingdom and Singapore

6 were contacted through their administrators and asked to publicise the study to their athletes.

7 Athletes who were willing to participate in the study were given a link to the online

8 questionnaire. According to online informed consent procedures, participants were told of the

9 purpose and details of the study through a participant information sheet. Participants were

10 informed that all responses would be kept strictly confidential and would only be used for the

11 purposes of the study. Having consented to participate in the study, participants filled in

12 relevant demographic information, including their age, gender, ethnicity, nationality,

13 education level, sport, level of sport participation, and number of years competing in the

14 sport. They were also asked if they had previous experience of working with a sport

15 psychology consultant, and were asked to evaluate whether they perceived their previous

16 sport psychology experience to be effective, and were satisfied with the services rendered.

17 Participants then proceeded to complete the SPA-R and NEO-FFI.

\section{Data Analysis}

All data analysis was conducted using SPSS 20.0. The first part of the data analysis involved a multivariate analysis of covariance (MANCOVA) with the participants' four SPA-

21 R scale scores as dependent variables, and their previous experience with a sport psychology

22 consultant as the covariate. Prior to running the MANCOVA, we tested for the assumptions

23 of the covariate. This protocol falls in line with research by Wrisberg et al. (2009), who

24 suggested that the effectiveness of previous sport psychology experience would affect sport

25 psychology attitudes. In accordance with past research (Martin, 2005; Martin et al., 2004), 
1 the MANCOVA sought to determine if the participants' sport psychology attitudes could be

2 differentiated by culture (Western and Eastern), gender (male and female), type of sport

3 (contact and non-contact), or any interaction between these factors.

4

The second part of the data analysis involved a series of multiple linear regression analyses that were conducted for each of the four variables of the SPA-R. Due to the lack of prior theory regarding the relationship between personality and sport psychology attitudes, the forced entry method was chosen for the multiple regression analyses, where all the predictor variables (i.e., the Big Five personality traits) were inputted into the regression equation simultaneously. The results were then analysed to determine how the Big Five personality traits predicted various attitudes towards sport psychology consulting in the athlete sample population.

\section{Results}

\section{Participants}

A total of 219 athletes ( $n=127$ males and 92 females) participated this study. All athletes were aged 18 and over $(M=22.39 S D=4.74)$, and were currently competing at school, club, county, or national level. A very wide variety of sports were represented, with 126 participants engaging in physical contact sports, and 93 participants engaging in noncontact sports. The definitions stated by Coakley (2001) were used for this study, with physical contact sports (e.g., rugby, football, judo) being characterised by bodily contact, intimidation, and physical injury; and non-contact sports (e.g., rowing, archery, sailing) being characterised by lack of physical contact or intimidation.

A total of 108 participants represented Western cultures ( $n=55$ males and 53 females), and 111 participants represented Eastern cultures ( $n=72$ males and 39 females).

The participants from Western cultures were predominantly of British nationality $(n=103)$, and most identified themselves ethnically as White $(n=93)$. The participants from Eastern 
1 cultures were predominantly of Singaporean nationality $(n=103)$, and most identified

2 themselves ethnically as Chinese $(n=97)$. More information about the demographics of the

3 participants from both Western and Eastern cultures can be found in Table 1.

[INSERT TABLE 1 HERE]

\section{Descriptive Statistics and Scale Reliabilities}

6

The basic descriptive statistics (means and standard deviations) for the SPA-R and NEO-FFI are shown in Table 2. For the SPA-R scores, the athletes had the highest scores for personal openness $(M=4.78, S D=0.85)$, and the lowest scores for stigma tolerance $(M=$ 2.57, $S D=0.95)$. As for the NEO-FFI scores, the athletes scoring highest in extraversion $(M$ $=3.56, S D=0.53)$, and lowest in neuroticism $(M=2.83, S D=0.69)$.

Estimates of internal consistency reliability (Cronbach's $\alpha$ ) ranged from 0.52 to 0.87 for the SPA-R, and 0.71 to 0.84 for the NEO-FFI.

\section{[INSERT TABLE 2 HERE]}

\section{MANCOVA}

Preliminary analysis. Based on past evidence (Wrisberg et al., 2009) stating that the effectiveness of previous sport psychology experience was associated with attitudes towards sport psychology consulting, a one-way multivariate analysis of variance (MANOVA) was conducted with effectiveness of past sport psychology experience as the independent variable and the four scales of the SPA-R as the dependent variables. The MANOVA showed significant differences in attitudes towards sport psychology according to the different past experiences of sport psychology consulting, Wilks’ Lambda $=.90, F(8,426)=3.01, p<.01$, $\eta^{2}=.05$. Due to the significant relationship that was found between past sport psychology experience and sport psychology attitudes, the effectiveness of past sport psychology experience was used as a covariate in the main analysis. 
Main analysis. A multivariate analysis of covariance (MANCOVA) was conducted using the four SPA-R scale scores as dependent variables and the effectiveness of the athletes’ past sport psychology experience as the covariate, to investigate if athletes’ attitudes towards sport psychology consulting could be differentiated by culture (Western and

5 Eastern), gender (male and female), type of sport (contact and non-contact), or any

6 interaction of these factors.

8 Lambda $=.81, F(4,207)=12.56, p<.001, \eta^{2}=.20$. Follow-up univariate analyses revealed 9 that stigma tolerance $\left[F(1,210)=17.89, p<.001, \eta^{2}=.08\right]$, personal openness $[F(1,210)=$ 15.96, $\left.p<.001, \eta^{2}=.07\right]$, and cultural preference $\left[F(1,210)=25.87, p<.001, \eta^{2}=.11\right]$ were the dependent variables that were significant (see Figure 1). Firstly, the responses of Western athletes $(M=2.33, S D=0.92)$ indicated that they were less likely to stigmatise sport psychology than Eastern athletes $(M=2.81, S D=.92)$. Secondly, Western athletes $(M=4.52$, $S D=0.78)$ had more personal openness to sport psychology than Eastern athletes $(M=5.04$, $S D=0.84)$. Finally, Western athletes $(M=2.88, S D=0.98)$ did not have as much preference for working with a sport psychology consultant of the same race and culture as Eastern athletes $(M=3.62, S D=1.10)$.

There was also a significant three-way interaction effect found for culture, gender, and type of sport, Wilks' Lambda $=.92, F(4,207)=4.69, p<.01, \eta^{2}=.08$. The univariate analyses revealed that stigma tolerance $\left[F(1,210)=8.44, p<.01, \eta^{2}=.04\right]$ and personal openness $\left[F(1,210)=6.41, p<.05, \eta^{2}=.03\right]$ were the dependent variables that were significant. A two-way univariate analysis was conducted for each level of culture, and a significant interaction between gender and type of sport was found for Eastern athletes, but not for Western athletes. Firstly, Eastern males who played contact sports $(M=2.80, S D=$ 
1 0.99) had lesser stigma towards sport psychology consulting than Eastern females who

2 played contact sports $(M=3.44, S D=0.93)$; however, there was no significant difference in

3 stigma tolerance between Eastern males and females who played non-contact sports $(M=$

$42.76, S D=0.82$, and $M=2.55, S D=0.78$, respectively). Secondly, Eastern male athletes who

5 played non-contact sports $(M=4.66, S D=1.02)$ had greater personal openness to sport

6 psychology than Eastern female athletes who played non-contact sports $(M=5.06, S D=$

7 0.60); on the other hand, Eastern male athletes who played contact sports $(M=5.27, S D=$

8 0.78) had lesser personal openness than Eastern female athletes who played contact sports ( $M$ $9 \quad=4.82, S D=0.86)$.

There were no main effects found for gender, Wilks’ Lambda $=0.96, F(4,207)=1.92$, $p>.05, \eta^{2}=.04$; type of sport, Wilks’ Lambda $=0.96, F(4,207)=1.94, p>.05, \eta^{2}=.04$; nor were there any other interaction effects found.

Multiple Linear Regression Analysis

An inspection of the variance inflation factor (VIF) among the independent variables did not reveal issues of multicollinearity (VIF ranged from 1.01 to 1.24). [INSERT TABLE 3 HERE]

Stigma tolerance. The multiple linear regression analysis (see Table 3 for all multiple regression analysis results) showed that the model significantly predicted stigma tolerance for the athlete sample $\left[F(5,213)=8.62, p<.001, R^{2}=.17, f^{2}=.20\right]$. This indicates that $17 \%$ of the variance in stigma tolerance can be explained by personality factors. Both conscientiousness $(\beta=-.30, t=-4.51, p<.001)$ and openness $(\beta=-.24, t=-3.83, p<.001)$

22 were found to be significant predictors of stigma tolerance. The results indicated that higher 23 levels of conscientiousness and openness predicted lesser stigma towards sport psychology 24 consulting. 
Confidence in sport psychology consulting. The multiple linear regression analysis showed that the model significantly predicted confidence in sport psychology consulting for

3 the athlete sample $\left[F(5,213)=5.45, p<.001, R^{2}=.11, f^{2}=.12\right]$. This indicates that $11 \%$ of

4 the variance in confidence in sport psychology consulting can be explained by personality

5 factors. Neuroticism $(\beta=.26, t=3.72, p<.001)$, conscientiousness $(\beta=.23, t=3.36, p<$

$6.01)$, and openness $(\beta=.15, t=2.37, p<.05)$ were found to be significant predictors of

7 confidence in sport psychology consulting. The results indicated that higher levels of

8 neuroticism, conscientiousness, and openness predicted greater confidence in sport

9 psychology consulting.

Personal openness. The multiple linear regression analysis showed that the model did not significantly predict personal openness in the athlete sample $[F(5,213)=0.76, p>$ $\left..05, R^{2}=.02, f^{2}=.02\right]$. This indicates that $2 \%$ of the variance in personal openness can be explained by personality factors. Therefore, the results suggest that none of the Big Five personality traits predicted personal openness in the athlete sample population.

Cultural preference. The multiple linear regression analysis showed that the model significantly predicted cultural preference for the athlete sample $\left[F(5,213)=3.18, p<.01, R^{2}\right.$

$\left.17=.07, f^{2}=.08\right]$. This indicates that $7 \%$ of the variance in cultural preference can be explained by personality factors. Only openness $(\beta=-.23, t=-3.45, p<.01)$ was found to be a significant predictor of cultural preference. The results showed that lower levels of openness predicted greater athlete preference for working with a sport psychology consultant of the same race or culture.

\section{Discussion}

The first aim of the study was to investigate and compare the sport psychology

24 attitudes of athletes from Western and Eastern cultures. Our tentative hypotheses were that

25 Eastern athletes would prefer working with consultants of the same culture, have less 
1 openness towards sport psychology consulting, but have more confidence in sport

2 psychology consulting, and lower stigma perceptions than Western athletes. The findings of

3 the study demonstrated only partial support for these hypotheses. On one hand, Eastern

4 athletes preferred working with consultants of the same culture and had less openness

5 towards sport psychology consulting, which was in line with previous literature. However,

6 they reported greater stigma towards sport psychology consulting than their Western

7 counterparts and were similar in terms of their confidence in sport psychology consulting - a

8 finding that contrasts with previous research by Naoi et al. (2011). A possible reason for the

9 difference in findings is that the majority of the Western athletes in the current study were

10 British, while all of the Western athletes surveyed in the Naoi et al. (2011) study were

11 American. In past research, Martin et al. (2004) found that American athletes had greater stigma towards sport psychology services and lesser confidence in such services than British athletes. Therefore, it is possible that the disparity in findings between the two studies could be due to sub-cultural differences between British and American athletes with respect to sport psychology attitudes.

In terms of explaining why Eastern athletes had less positive attitudes towards sport psychology consulting compared to Western athletes, Araki and Balasekaran (2009) stated that sport psychology development in Singapore is still in its infancy compared to a welldeveloped sporting nation like UK. Therefore, there is not much education regarding the benefits of sport psychology amongst Singaporean athletes, which could possibly result in

21 them not being as open towards sport psychology consulting compared to their British counterparts. Terry (2009) also added that Asian athletes are often reluctant to discuss

23 limitations or worries with a sport psychology consultant, and that this usually persists until 24 rapport and trust is developed. He also mentioned that Chinese athletes might not be open to 25 seeing a sport psychology consultant as it might be construed as a shameful act and might 
1 bring dishonour to their family or cultural group. This would also help to explain why the

2 Chinese Singaporean athletes in this study were less open to engaging in sport psychology

3 consulting compared to White British athletes. In addition, Araki and Balasekaran (2009)

4 also stated that Singaporean athletes are highly submissive, and are not comfortable with

5 voicing their opinion or making decisions on their own. As such, they might be more

6 comfortable working with a local sport psychology consultant who understands their specific

7 communication style, as compared to a foreign consultant who might not understand their

8 unique mannerisms.

Another notable observation was that while Western athletes had greater openness to sport psychology consulting than Eastern athletes, their mean score obtained of 4.52 was still relatively high. This suggests that while Western athletes may be more open towards sport psychology consulting than Eastern athletes, the mean score still reflects a certain degree of reluctance to try sport psychology consulting. This is in line with previous research conducted in Western contexts (Green et al., 2012; Pain and Harwood, 2004) which suggested that some Western athletes might still not be open to engaging in sport psychology consulting.

There were also no significant main effects observed for gender or type of sport. This lies contrary to previous literature (Anderson et al., 2004; Martin, 2005; Martin et al., 2004; Wrisberg et al., 2009), which suggested that gender and type of sport both have an influence on athletes’ sport psychology attitudes. However, there was a significant three-way interaction effect observed for culture, gender and type of sport. This is in line with previous literature relating to sub-culture in sport psychology (Coulter, Mallett, \& Singer, 2016; Schinke \& McGannon, 2014), where the authors advocate the need to critically consider the athlete's specific background and context in order to fully appreciate their attitudes towards sport psychology. This three-way interaction effect reflects the complexity that exists within 
1 each individual athlete, and suggests that athletes cannot be stereotyped purely based on

2 broad categories. For example, Eastern males who played contact sports were found to have

3 less stigma towards sport psychology consulting, but yet also had less personal openness

4 towards it as compared to Eastern females who played contact sports. However, in terms of

5 non-contact sport athletes, it was Eastern males who had greater personal openness instead of

6 Eastern females.

\section{$7 \quad$ Personality and Sport Psychology Attitudes}

The second aim of this study was to investigate whether athletes’ Big Five personality

traits would predict their attitudes towards sport psychology consulting (i.e., stigma tolerance, confidence in sport psychology consulting, personal openness, and cultural preference). The

11 hypothesis was that high extraversion, neuroticism, agreeableness, openness, and low conscientiousness would predict more positive attitudes towards sport psychology consulting.

Once again, the findings of this study showed mixed support for the hypothesis. On one hand, certain personality traits such as openness and neuroticism predicted positive attitudes towards sport psychology consulting; but on the other hand, traits such as extraversion and agreeableness did not show any significant relation to sport psychology attitudes. Early conjectures based on past research (Atik \& Yalcin, 2011; Kakhnovets, 2011) suggest that individuals with higher openness may be more willing to try new things and explore whether sport psychology can help them; and those with higher neuroticism may be less emotionally stable and might have more impetus for seeking out sport psychology help. However, further research needs to be conducted to fully ascertain the reasons behind the findings. 
1 conscientiousness was associated with lower acceptance of psychological support services.

2 However, it must be noted that the study by Seekles et al. (2012) investigated clinically

3 depressed patients, and it is possible that more mentally healthy athletes who participated in

4 this study would have a very different response towards seeking psychological help from a

5 sport-specific professional. Since individuals with high conscientiousness are more organised

6 and detail-orientated (McCrae \& John, 1992), it is possible that they might have done some

7 background research to find out more about the benefits of sport psychology. This would

8 have equipped them with a greater understanding of how sport psychology can help them,

9 and thus increase their acceptance of sport psychology services.

The results also showed that none of the Big Five personality traits predicted personal openness in athletes. This non-significant finding might appear to be rather surprising due to the similarity in definitions of openness used in the SPA-R and the Big Five model. In the SPA-R, the construct of personal openness is characterised by a willingness to engage in sport psychology consultation (Martin et al., 2002); while in the Big Five model, the personality trait of openness is described as a willingness to try new things (McCrae \& John, 1992). More research needs to be conducted to fully examine how these two constructs might be related to each other. cultural preference. It was found that higher levels of openness predicted lesser preference for working with a sport psychology consultant of the same race or culture. This is in line with

21 previous research by Flynn (2005), who found that individuals with higher openness were 22 less prejudiced towards people of other races as they placed greater importance in obtaining 23 novel information from new sources. Therefore, such individuals would be more willing to 24 work with a sport psychology consultant of a different culture so that they might gain new 25 perspectives and ideas to improve their sporting performance. 


\section{Practical Implications}

The findings of this study offer a number of implications and considerations for consultants with respect to making their service provision more attractive to a wider range of athletes. In terms of working with athletes from Eastern and Western cultures, there appear to

5 be several significant differences in their attitudes towards sport psychology consulting. On a

6 whole, Eastern athletes appear to stigmatise sport psychology consulting more, be less open

7 to engaging in sport psychology consulting, and have greater preference for working with a

8 consultant of the same race or culture than Western athletes. This is explained by Shea and

9 Yeh (2008), who suggested that Eastern individuals might find seeking psychological help to

10 be in conflict with their cultural belief system, due to the strong Eastern emphasis on

11 restraining one's feelings and enduring pain for the sake of social harmony. Therefore, sport psychology consultants need to do more to reach out and explain their services to Eastern athletes, so as to make sport psychology more accessible and attractive to them. Sport psychology consultants also need to have greater sensitivity towards how their athletes might manifest collectivism or individualism in accordance to their cultural background. This will

16 help them to better understand the level of resistance that their athletes might have towards sport psychology, and enable them to adjust their service delivery approach accordingly. consulting, but their attitudes can vary as function of their gender and sport type. For Eastern

20 female athletes who play contact sports, sport psychology consultants may need to spend 21 more time addressing the stigmas that they might have towards sport psychology consulting.

22 As for Eastern male athletes who play contact sports, they may need to put extra effort into

23 building rapport and gaining entry with such athletes before they are willing to accept sport 24 psychology services. 
In terms of gaining entry with their athletes, sport psychology consultants may consider assessment of the Big Five personality traits of their athletes before starting work with them. After benchmarking their athletes’ personality scores against established norms, the consultant may be able to interpret the findings to facilitate better acceptance and effectiveness in their work with the athlete. Based on the findings of this study, sport psychology consultants should seek to debunk certain stigma associated with sport psychology in athletes who have low conscientiousness and low openness. They should also endeavour to explain the potential benefits of sport psychology to athletes with low conscientiousness, openness, and neuroticism. This will help to instill a greater amount of confidence towards sport psychology consulting in such athletes. Lastly, when working with athletes of a difference race or culture, they should be aware that athletes with low openness might have certain prejudices and biases towards the consultant. Thus, they should make an extra effort to reach out to such athletes in the process of sensitive rapport building.

The findings of this study also have various implications for the training of young sport psychology practitioners. Improved education for young practitioners in the area of personality and its assessment may be valuable in terms enhancing tools for marketing, service promotion, and overall service delivery.

\section{Limitations and Future Directions}

An acknowledged limitation of this study is that the participants surveyed were not a random representation of athletes from Eastern and Western cultures. As mentioned earlier, the athletes from Eastern cultures were predominantly of Singaporean nationality (93\%), and the participants from Western cultures were predominantly of British nationality (95\%). Even though Singapore has strong roots in Eastern culture and is deeply entrenched in Asian and

Confucian values (Araki \& Balasekaran, 2009), it has also been identified as a very cosmopolitan and globalised country, where Western and Eastern values both feature very 
1 prominently in society (Xinyi, Smith, \& Adegbola, 2004). Therefore, future research should

2 seek to compare Singaporean athletes with athletes from more traditional Eastern nations

3 (e.g., China, Japan, Korea), to identify how athletes in those countries might differ in terms of

4 their sport psychology attitudes. As for athletes of British nationality, they typically represent

5 the ethnocentric white perspective that has dominated sport psychology research (Kontos \&

6 Breland-Noble, 2002). However, previous literature has indicated that there still exist various

7 differences between Western athletes of different nationalities. For example, British athletes

8 were found to differ from American or German athletes in terms of stigma tolerance,

9 confidence in sport psychology consulting, and cultural preference (Martin et al., 2004).

10 Therefore, future research should also be conducted with athletes of other Western

11 nationalities in order to fully understand the fine nuances that define their attitudes towards 12 sport psychology consulting.

13 Another key limitation was that most of the athletes surveyed in this study were

14 highly educated (95\% attended college, university or higher), which might threaten the 15 applicability of the results to less highly educated athletes.

16 Although the results of this study provide useful insight into how personality and 17 culture affect the sport psychology attitudes of athletes, future research needs to be conducted 18 to identify why certain personality traits might affect specific attitudes. Qualitative analysis 19 should be conducted with athletes of various personality types to uncover their thoughts and 20 attitudes towards sport psychology consulting. This would enable an additional, richer 21 understanding of how various personality traits might affect sport psychology attitudes.

\section{Conclusion}

23 In summary, this study found that athletes from Eastern and Western cultures differed 24 significantly in terms of their attitudes towards sport psychology consulting. Western athletes 25 had lesser stigma towards sport psychology consulting, greater personal openness, and lesser 
1 preference for a consultant of the same race or culture than Eastern athletes. The study also

2 found that certain personality traits predicted athletes' attitudes towards sport psychology

3 consulting. High conscientiousness and openness predicted lesser stigma towards sport

4 psychology consulting; high conscientiousness, openness, and neuroticism predicted greater

5 confidence in sport psychology consulting; and finally, low openness predicted greater

6 preference for a consultant of the same race or culture. In offering fresh insights into how

7 culture and personality affect athletes' attitudes towards sport psychology consulting, we

8 hope that this study triggers further investigation into the cultural and individual factors that

9 matter when optimising engagement in sport psychology services. 


\section{References}

2 Amirkhan, J. H., Risinger, R. T., \& Swickert, R. J. (1995). Extraversion: A “hidden” personality factor in coping?. Journal of Personality, 63, 189-212. doi:10.1111/j.1467-6494.1995.tb00807.x

Anderson, A. G., Hodge, K. P., Lavallee, D., \& Martin, S. B. (2004). New Zealand athletes' attitudes towards seeking sport psychology consultation. New Zealand Journal of Psychology, 33, 129-136.

Anderson, M. B. (1993). Questionable sensitivity: A comment on Lee and Rotella. The Sport Psychologist, 7, 1-3. doi:10.1123/tsp.7.1.1

Araki, K., \& Balasekaran, G. (2009). Singaporean athletes in a multicultural society. In R. J. Schinke \& S. J. Hanrahan (Eds.), Cultural sport psychology (pp. 193-203). Champaign, IL: Human Kinetics.

Asghar, E., Wang, X., Linde, K., \& Alfermann, D. (2013). Comparisons between Asian and German male adolescent athletes on goal orientation, physical self-concept, and competitive anxiety. International Journal of Sport and Exercise Psychology, 11, 229-243. doi:10.1080/1612197X.2013.748999

Atik, G., \& Yalçin, Y. (2011). Help-seeking attitudes of university students: the role of personality traits and demographic factors. South African Journal of Psychology, 41, 328-338.

Bathje, G. J., Kim, E., Rau, E., Bassiouny, M. A., \& Kim, T. (2014). Attitudes toward Face-to-Face and Online Counseling: Roles of Self-Concealment, Openness to Experience, Loss of Face, Stigma, and Disclosure Expectations among Korean College Students. International Journal for the Advancement of Counselling, 36, 408422. doi:10.1007/s10447-014-9215-2

Coakley, J. J. (2001). Sport in society: Issues and controversies (7th ed.). Boston: 
McGraw-Hill.

2 Connaughton, D., Wadey, R., Hanton, S., \& Jones, G. (2008). The development and maintenance of mental toughness: Perceptions of elite performers. Journal of Sports Sciences, 26, 83-95. doi:10.1080/02640410701310958

Costa, P. T. Jr., \& McCrae, R. R. (1992). Revised NEO Personality Inventory (NEOPI-R) and NEO Five-Factor Inventory (NEO-FFI) professional manual. Odessa, FL: Psychological Assessment Resources.

Coulter, T. J., Mallett, C. J., \& Singer, J. A. (2016). A subculture of mental toughness in an Australian Football League club. Psychology of Sport and Exercise, 22, 98-113. doi:10.1016/j.psychsport.2015.06.007

Flynn, F. J. (2005). Having an open mind: the impact of openness to experience on interracial attitudes and impression formation. Journal of Personality and Social Psychology, 88, 816-826. doi:10.1037/0022-3514.88.5.816

Friedman, B., Veazie, P. J., Chapman, B. P., Manning, W. G., \& Duberstein, P. R. (2013). Is personality associated with health care use by older adults?. Milbank Quarterly, 91, 491-527. doi:10.1111/1468-0009.12024

Greenleaf, C., Gould, D., \& Dieffenbach, K. (2001). Factors influencing Olympic performance: interviews with Atlanta and Negano US Olympians. Journal of Applied Sport Psychology, 13, 154-184. doi:10.1080/104132001753149874

Gould, D., \& Maynard, I. (2009). Psychological preparation for the Olympic Games. Journal of Sports Sciences, 27, 1393-1408. doi:10.1080/02640410903081845

Green, M., Morgan, G., \& Manley, A. (2012). Elite rugby league players’attitudes towards sport psychology consulting. Sport \& Exercise Psychology Review, 8, 32-44.

Hopwood, C. J., Quigley, B. D., Grilo, C. M., Sanislow, C. A., McGlashan, T. H., 

Yen, S., ... \& Markowitz, J. C. (2008). Personality traits and mental health treatment utilization. Personality and Mental Health, 2, 207-217.

Kakhnovets, R. (2011). Relationships among Personality, Expectations about Counseling, and Help-Seeking Attitudes. Journal of Counseling \& Development, 89, 11-19. doi:10.1002/j.1556-6678.2011.tb00056.x

Karageorghis, C.I., \& Terry, P.C. (2011). Inside sport psychology. Champaign, IL: Human Kinetics.

Klockner, K. D., \& Hicks, R. E. (2008). My next client: Understanding the Big Five and positive personality dispositions of those seeking psychosocial support interventions. Coaching Psychology Review, 3, 148-163.

Komiya, N., Good, G. E., \& Sherrod, N. B. (2000). Emotional openness as a predictor of college students' attitudes toward seeking psychological help. Journal of Counseling Psychology, 47, 138-143. doi:10.1037/0022-0167.47.1.138

Kontos A. P., \& Breland-Noble, A. M. (2002). Racial/ethnic diversity in applied sport psychology: A multicultural introduction to working with athletes of color. The Sport Psychologist, 16, 296-315. doi:10.1123/tsp.16.3.296

Kremer, J., \& Moran, A.P. (2012). Pure sport: Practical sport psychology. London: Routledge.

Lavallee, D., Jennings, D., Anderson, A. G., \& Martin, S. B. (2005). Irish athletes' attitudes toward seeking sport psychology consultation. The Irish Journal of Psychology, 26, 115-121. doi:10.1080/03033910.2005.10446214

Lubker, J. R., Visek, A. J., Watson, J. C., \& Singpurwalla, D. (2012). Athletes’ preferred characteristics and qualifications of sport psychology practitioners: A consumer market analysis. Journal of Applied Sport Psychology, 24, 465-480. doi:10.1080/10413200.2012.694968 
1 Martin, S. B. (2005). High school and college athletes' attitudes toward sport psychology consulting. Journal of Applied Sport Psychology, 17, 127-139. doi:10.1080/10413200590932434

Martin, S. B., Kellmann, M., Lavallee, D., \& Page, S. J. (2002). Development and psychometric evaluation of the sport psychology attitudes--Revised form: A multiple group investigation. The Sport Psychologist, 16, 272-290. doi:10.1123/tsp.16.3.272

Martin, S. B., Lavallee, D., Kellmann, M., \& Page, S. J. (2004). Attitudes toward sport psychology consulting of adult athletes from the United States, United Kingdom, and Germany. International Journal of Sport and Exercise Psychology, 2, 146-160. doi:10.1080/1612197X.2004.9671738

Martin, S. B., Wrisberg, C. A., Beitel, P. A., \& Lounsbury, J. (1997). NCAA Division I athletes' attitudes toward seeking sport psychology consultation: The development of an objective instrument. The Sport Psychologist, 11, 201-218. doi:10.1123/tsp.11.2.201

Martin, S. B., Zakrajsek, R. A., \& Wrisberg, C. A. (2012). Attitudes toward sport psychology and seeking assistance: Key factors and a proposed model. In C. D. Logan, M. I. Hodges (Eds.), Psychology of Attitudes (pp. 1-33). Hauppauge, NY: Nova Science Publishers.

McCrae, R. R., \& John, O. P. (1992). An introduction to the five-factor model and its applications. Journal of Personality, 60, 175-215. doi:10.1111/j.14676494.1992.tb00970.x

McGannon, K.R., \& Johnson, C.R. (2009). Strategies for reflective cultural sport psychology research. In R.J. Schinke \& S.J. Hanrahan (Eds.), Cultural sport psychology (pp. 5775). Champaign, IL: Human Kinetics.

Naoi, A., Watson, J., Deaner, H., \& Sato, M. (2011). Multicultural issues in sport 
psychology and consultation. International Journal of Sport and Exercise Psychology, 9, 110-125. doi:10.1080/1612197X.2011.567101

Nocita, A., \& Stiles, W. B. (1986). Client introversion and counseling session impact. Journal of Counseling Psychology, 33, 235-241. doi:10.1037/0022-0167.33.3.235

Pain, M. A., \& Harwood, C. G. (2004). Knowledge and perceptions of sport psychology within English soccer. Journal of Sports Sciences, 22, 813-826. doi:10.1080/02640410410001716670

Ravizza, K. (1988). Gaining entry with athletic personnel for season-long consulting. The Sport Psychologist, 2, 243-254. doi:10.1123/tsp.2.3.243

Ravizza, K. (2001). Reflections and insights from the field on performance enhancement consultation. In G. Tenenbaum (Ed.), The practice of sport psychology (pp. 197-216). Morgantown, WV: Fitness Information Technology, Inc.

Ryba, T. V., Stambulova, N. B., Si, G., \& Schinke, R. J. (2013). ISSP position stand: Culturally competent research and practice in sport and exercise psychology. International Journal of Sport and Exercise Psychology, 11, 123-142. doi:10.1080/1612197X.2013.779812

Schinke, R. J., \& McGannon, K. R. (Eds.). (2014). The psychology of sub-culture in sport and physical activity: Critical perspectives. New York: Routledge.

Schinke, R.J., McGannon, K.R., Parham, W.D., \& Lane, A. (2012). Toward cultural praxis: Strategies for self-reflexive sport psychology practice. Quest, 64, 34-46. doi:10.1080/00336297.2012.653264

Seekles, W. M., Cuijpers, P., Van de Ven, P., Penninx, B. W. J. H., Verhaak, P. F. M., Beekman, A. T. F., \& Van Straten, A. (2012). Personality and perceived need for mental health care among primary care patients. Journal of Affective Disorders, 136, 666-674. doi:10.1016/j.jad.2011.10.009 
1 Shea, M., \& Yeh, C. J. (2008). Asian American students' cultural values, stigma, and relational self-construal: Correlates of attitudes toward professional help seeking. Journal of Mental Health Counseling, 30, 157-172. doi:10.17744/mehc.30.2.g662g5l2r1352198

Terry, P.C. (2009). Strategi es for reflective sport-psychology practice. In R.J. Schinke \& S.J. Hanrahan (Eds.), Cultural sport psychology (pp. 79-89). Champaign, IL: Human Kinetics.

Tsan, J. Y., \& Day, S. X. (2007). Personality and gender as predictors of online counseling use. Journal of Technology in Human Services, 25, 39-55. doi:10.1300/J017v25n03_03

Vogel, D. L., Wade, N. G., \& Hackler, A. H. (2007). Perceived public stigma and the willingness to seek counseling: The mediating roles of self-stigma and attitudes toward counseling. Journal of Counseling Psychology, 54, 40-50. doi:10.1037/00220167.54.1.40

Wrisberg, C. A., Simpson, D., Loberg, L. A., Withycombe, J. L., \& Reed, A. (2009). NCAA Division-I student-athletes' receptivity to mental skills training by sport psychology consultants. The Sport Psychologist, 23, 470-486. doi:10.1123/tsp.23.4.470

Xinyi, Z., Smith, D., \& Adegbola, O. (2004). A cross-cultural comparison of six mental qualities among Singaporean, North American, Chinese, and Nigerian professional athletes. International Journal of Sport and Exercise Psychology, 2, 103118. doi:10.1080/1612197X.2004.9671735

Yambor, J., \& Connelly, D. (1991). Issues confronting female sport psychology consultants working with male student-athletes. The Sport Psychologist, 5(4), 304312. doi:10.1123/tsp.5.4.304 
Tables

Table 1

Demographic information of Western and Eastern culture participants

\begin{tabular}{|c|c|c|c|}
\hline & Western $(n=108)$ & Eastern $(n=111)$ & Combined $(n=219)$ \\
\hline \multicolumn{4}{|l|}{ Gender } \\
\hline Male & 55 & 72 & 127 \\
\hline Female & 53 & 39 & 92 \\
\hline Age & $21.96(5.66)$ & $22.81(3.60)$ & $22.39(4.74)$ \\
\hline Years of Sport Experience & $8.93(5.73)$ & $6.58(4.98)$ & $7.74(5.48)$ \\
\hline \multicolumn{4}{|l|}{ Education Level } \\
\hline High School or Lower & 2 & 10 & 12 \\
\hline College/Undergraduate & 96 & 92 & 188 \\
\hline Postgraduate & 10 & 9 & 19 \\
\hline \multicolumn{4}{|l|}{ Level of Sport Participation } \\
\hline School & 20 & 48 & 68 \\
\hline Club & 43 & 41 & 84 \\
\hline County & 22 & 3 & 25 \\
\hline National & 23 & 19 & 42 \\
\hline \multicolumn{4}{|l|}{ Type of Sport } \\
\hline Contact & 65 & 61 & 126 \\
\hline Non-Contact & 43 & 50 & 93 \\
\hline \multicolumn{4}{|l|}{ Previous Sport Psychology } \\
\hline \multicolumn{4}{|l|}{ Experience } \\
\hline None & 90 & 98 & 188 \\
\hline Yes (Effective) & 12 & 10 & 22 \\
\hline Yes (Ineffective) & 6 & 3 & 9 \\
\hline
\end{tabular}

2

3

4

5

6

7

8

9

10

11

12 
Table 2

Means and standard deviations for Western and Eastern culture participants

\begin{tabular}{lccc}
\hline & Western $(n=108)$ & Eastern $(n=111)$ & Combined $(n=219)$ \\
\hline Personality & & & \\
Extraversion & $3.70(0.49)$ & $3.42(0.53)$ & $3.56(0.53)$ \\
Neuroticism & $2.81(0.73)$ & $2.86(0.64)$ & $2.83(0.69)$ \\
Agreeableness & $3.46(0.48)$ & $3.53(0.41)$ & $3.50(0.45)$ \\
Conscientiousness & $3.76(0.52)$ & $3.47(0.51)$ & $3.61(0.54)$ \\
Openness & $3.22(0.50)$ & $3.26(0.52)$ & $3.24(0.51)$ \\
& & & \\
Sport Psychology Attitudes & & & \\
Stigma Tolerance & $2.33(0.92)$ & $2.81(0.92)$ & $2.57(0.95)$ \\
Confidence in Sport Psychology & $4.55(1.04)$ & $4.68(0.96)$ & $4.61(1.00)$ \\
Personal Openness & $4.52(0.78)$ & $5.04(0.84)$ & $4.78(0.85)$ \\
Cultural Preference & $2.88(0.98)$ & $3.62(1.10)$ & $3.25(1.10)$ \\
\hline
\end{tabular}

1

2

3

4

5

6

7

8

9

10

11

12

13

14

15

16

17

18

19 


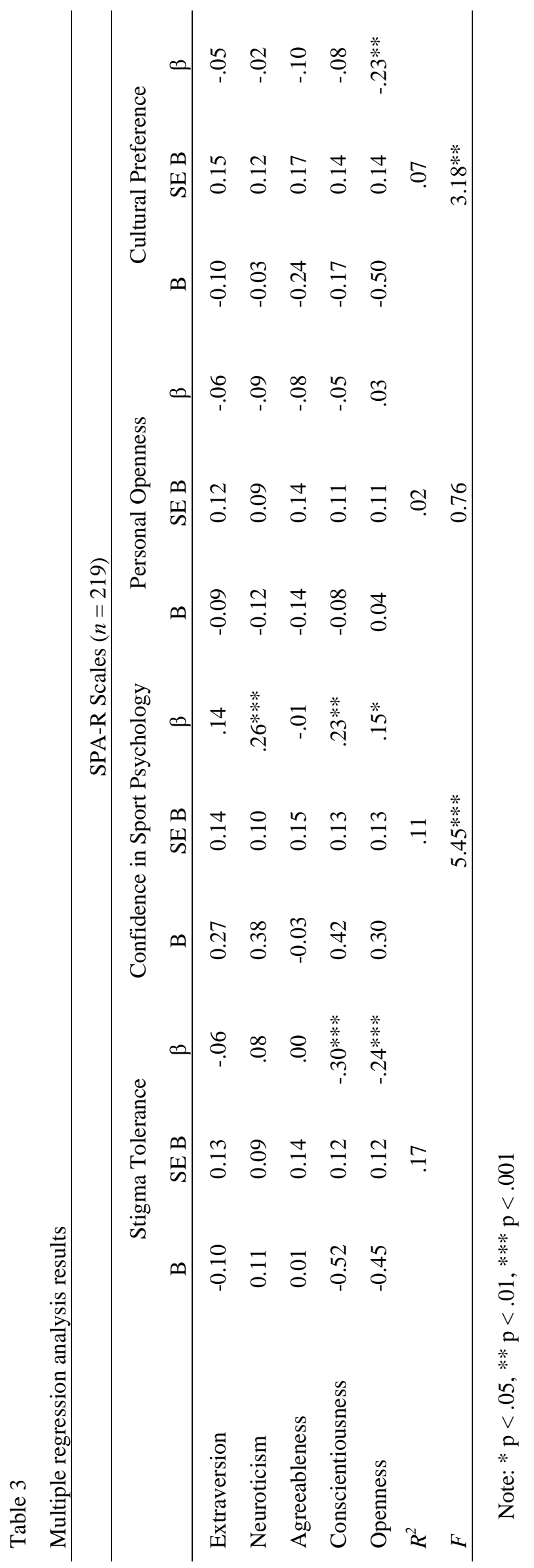


2 Figure 1. Mean scores of SPA-R subscales as a function of culture.

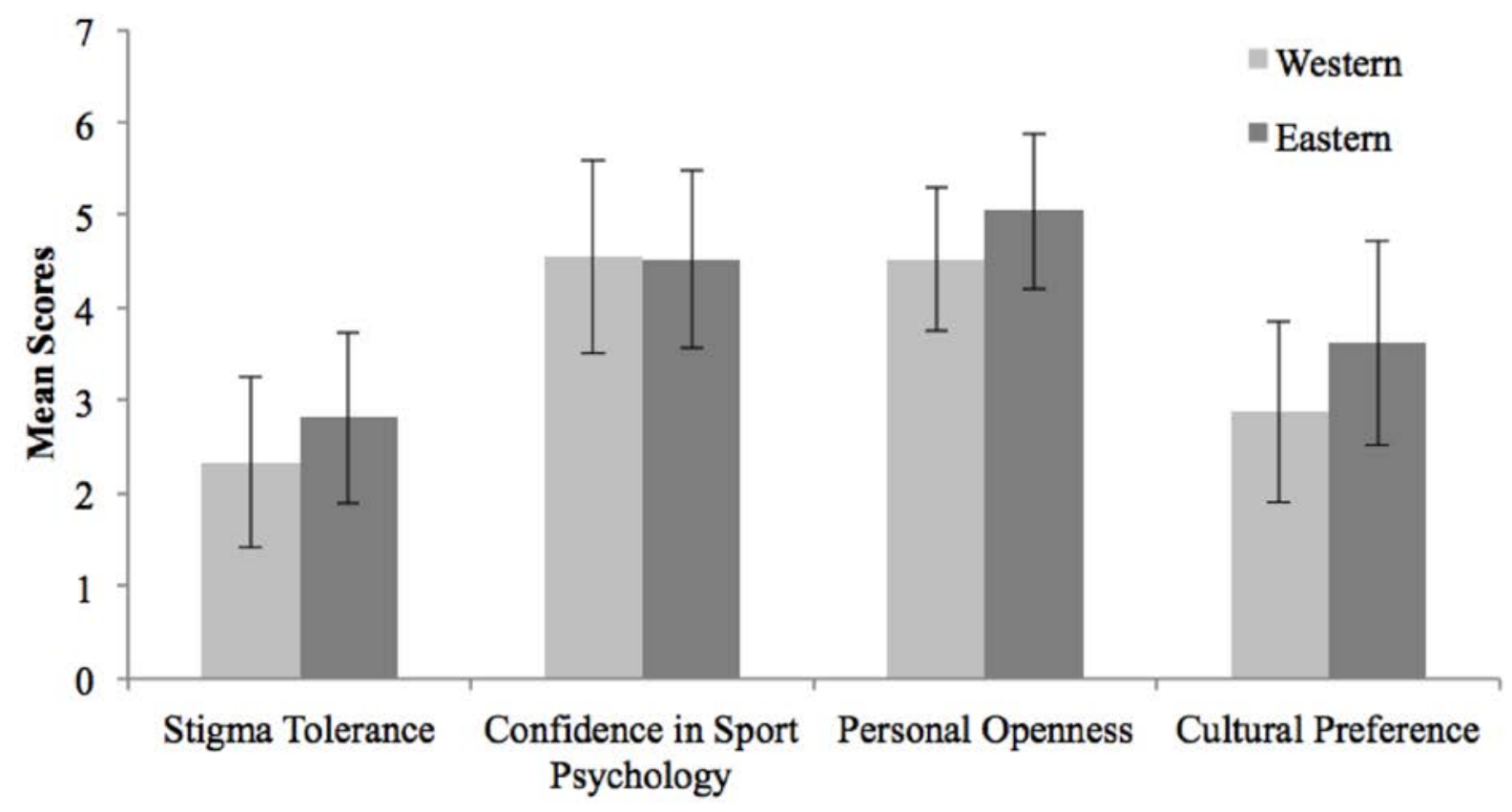

